\title{
The First COVID- I 9 Incidence in India: A Lesson of Struggle and Survival
}

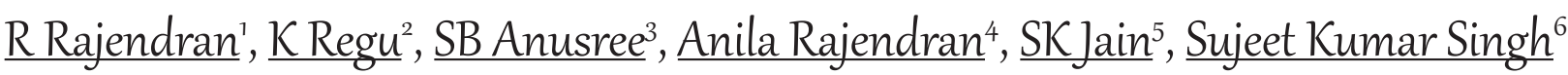

\author{
${ }^{1,}$ Deputy Director, ${ }^{2}$ Additional Director, ${ }^{3,4}$ Research Assistant, National Centre for Disease Control, Government of India, Calicut, \\ Kerala, India. \\ ${ }^{5}$ Additional Director, ${ }^{6}$ Director, National Centre for Disease Control, Ministry of Health \& Family Welfare, Government of India, \\ 22 Sham Nath Marg, Delhi, India. \\ DOI: https://doi.org/10.24321/0019.5138.202018
}

\section{I $\quad \mathbf{N} \quad \mathbf{F} \quad \mathbf{O}$}

\author{
Corresponding Author: \\ R Rajendran, National Centre for Disease Control, \\ Government of India, Calicut, Kerala, India. \\ E-mail Id: \\ rajendran061@gmail.com \\ Orcid Id: \\ https://orcid.org/0000-0003-2080-9723 \\ How to cite this article: \\ Rajendran R, Regu K, Anusree SB, Rajendran A, \\ Jain SK, Singh SK. The First COVID-19 Incidence \\ in India: A Lesson of Struggle and Survival. J \\ Commun Dis 2020; 52(2): 25-31.
}

Date of Submission: 2020-05-16

Date of Acceptance: 2020-06-11

\section{$\begin{array}{llllllll}\mathbf{A} & \mathbf{B} & \mathbf{S} & \mathbf{T} & \mathbf{R} & \mathbf{A} & \mathbf{C} & \mathbf{T}\end{array}$}

The coronavirus disease 2019 (COVID-19) outbreak, which originated in Wuhan, China, has now spread to more than 200 countries and administrative regions infecting 3,09,04,45 individuals of all ages as of $3^{\text {rd }}$ April, 2020. Though most of the infected individuals exhibit mild symptoms including fever, upper respiratory tract infections, shortness of breath and diarrhea or are asymptomatic altogether. Severe cases of infection can lead to pneumonia, multiple organ failure and death. Globally, at least 2, 07,973 deaths have been directly attributed to COVID-19 and this number is expected to rise with the ongoing epidemic. WHO declared the outbreak to be a public health Emergency of International concern on January 30, 2020. The same day, a laboratory confirmed case of COVID-19 was reported in Kerala. That was the first reported case of COVID-19 in India. Since then 498 disease cases were reported in Kerala, while in India this has gone up to 33,050 with 1,074 deaths. During the first phase of the COVID-19 outbreak in Kerala, the health authorities have responded in a stellar manner. Kerala has not only traced hundreds of contacts of the confirmed cases and notified them to the Integrated Disease Surveillance Programme (IDSP) for monitoring, but also used unique community-based isolation methods, innovated while dealing with the Nipah virus outbreaks of 2018 and 2019. The model of monitoring with the District Collector as the administrative unit has been shared as a best practice with all states.

Keywords: 2019-nCoV, COVID-19, Emergency Preparedness, Surveillance Strategy, Sanitization Practice

\section{Introduction}

In late December 2019, a cluster of pneumonia cases, caused by a newly identified coronavirus, was reported by health authorities in Wuhan, Hubei Province, People's Republic of China. According to the South Morning Post dated Nov.17, 2019, a 55 yrs. old individual form Hubei province in China was reported to be the first person to have contracted COVID-19, the disease caused by the new coronavirus. The preliminary cases mostly had connections to the Huanan Seafood Wholesale Market and hence, the virus is thought to have a zoonotic origin. However, the earliest reported symptoms occurred in Wuhan on 1st 
December 2019, in a person who did not have exposure to the seafood market. This prompted the researchers to think the origin of the virus other than seafood market. Meanwhile, the Chinese scientists isolated the virus from a patient on January 7, 2020 and came out to genome sequencing of SARS CoV-2. ${ }^{1}$

The first case of the coronavirus epidemic was discovered with unexplained pneumonia on December 12, 2019, and 27 viral pneumonia cases with seven being severe, were officially announced on December 31, 2019. ${ }^{2}$ This coronavirus was initially named as the 2019 novel coronavirus (2019-nCoV) on 12 January 2020 by World Health Organization (WHO). On January 22, 2020, novel $\mathrm{CoV}$ has been declared to be originated from wild bats and belonged to Group 2 of beta-coronavirus that contain Severe Acute Respiratory Syndrome Associated Coronavirus (SARS-CoV). On 11 February 2020, WHO officially named the disease as coronavirus disease 2019 (COVID-19). ${ }^{3}$

COVID-19 outbreak occurred in China during the spring festival. During this time, about 3 billion people travelled nationwide. This condition favored for the transmission of this highly infectious disease. It is worthwhile to note that the SARS epidemic peaked in China during the same spring season in 2003. Wuhan is the epicenter of this highly contagious disease especially as it facilitates most of the transport services during the spring festival. The number of travelers during 2020 rose to 1.7 folds when compared to 2003 SARS outbreak. The free movement of people favored the spread of COVID-19 to a great extent. ${ }^{4}$

\section{The Entry and Establishment of COVID-19 in India}

Every year hundreds of Kerala students are moving to China for higher studies, especially in the field of Medical education. Many other Keralites are either having their own business centers/ or working in different sectors in almost all provinces of China. The well-to-do people frequently visits Kerala. However, the students who are pursuing their studies in China may come once in a year or after the completion of the course depending on the availability of holidays or situation demands. Every year the students and other people used to come to Kerala during New Year holidays. This time, a cluster of pneumonia cases of unknown origin started appearing in Wuhan, Hubei Province of China in the dawn of New Year. In the beginning, the local authorities and inhabitants of Wuhan gave less attention to this 'flu' disease. It appears that the 'disease germ' appeared in Hubei Province in mid-November and started its activity so silently. The number of pneumonia cases rose to 27 in mid-December. The disease outbreak was officially announced on $31^{\text {st }}$ December, i.e., after one and half month of the first case reported in the Province. During this time the virus could freely move in the environment. By January $23^{\text {rd }} 2020$ the number of cases rose to 571 . In the midst of this, without knowing the forthcoming danger of the ' $f l u$ ', some of the students started from Wuhan to Kerala.

\section{Historic Announcement}

On January 30, 2020, the Health Minister of Kerala at around 14.00 hours made a formal announcement on television. "The first imported case of the novel coronavirus (COVID-19) in India had been confirmed in Kerala. The patient was being monitored at the General Hospital located at Thrissur. The patient was a 20 year old female medical student who had returned home from Wuhan, the epicenter of the COVID-19

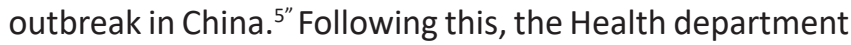
has taken all the measures to arrange isolation wards in major hospitals and a helpline was activated in every district.

\section{Case History of the First COVID-I9 Patient in India}

The female student, a native of Thrissur district, was one of the hundreds of Malayali medical students studying in Wuhan University in Hubei province. She had come home for the Lunar New Year holidays. She started the journey on January 23, 2020 from Wuhan to Kunming along with 15 students by train. On the same day, she started from Kunming airport to Kolkata by China East flight, reached Kolkata on $24^{\text {th }}$ January and stayed at airport for more than eight hrs. On $24^{\text {th }}$ January, she started from Kolkata along with 27 students and reached Kochi by Indigo flight. At the airport, she was received by parents and her brother. Seeing an alert about the virus, on $25^{\text {th }}$ January, she had gone to the nearest primary health centre at Mathilakam to inform the health officials about her arrival. As she did not have any symptoms then, the officials gave her the contact number of the District Surveillance Officer (DSO) and asked her to dial the official in case she develops the flu like symptoms. She developed fever, cough and sore throat on $27^{\text {th }}$ January; she promptly contacted the officer and was rushed to the hospital. She was placed in the isolation ward of General hospital, Thrissur and her blood/throat swab samples were collected and sent to National Institute of Virology, Pune for testing. On January 30, 2020, results came as positive. This is the first confirmed COVID-19 case in India. She was shifted to the Government Medical College Hospital, Thrissur. Eighty-two contact cases were identified. Out of this, only 28 people were developed symptoms. Their samples were sent to NIV, Pune for testing. All the samples were found negative.

The patient was strictly monitored and treatment was given as per the protocol. She was stable in all these days and discharged on February 20, 2020 after the consecutive samples were found negative.

\section{Emergency Preparedness}

Late in December, when news about the mystery virus 
trickled in, Kerala, like rest of the world, watched the evolving situation, concerned. In China, during the early stages, the number of COVID-19 cases doubled approximately in every seven and a half days. On January 30, 2020, Director-General WHO declared that the outbreak of COVID-19 constitutes a Public Health Emergency of International concern (PHEIC) as per the advice of International Health Regulations (IHR) Emergency Committee. It is quite coincidence that the first Lab confirmed COVID-19 case reported in India is also on the same day. As on $31^{\text {st }}$ January 2020 , a total of 9720 confirmed cases and 213 deaths have been reported in China. The epicenter of the outbreak was initially in Wuhan city, Hubei province but has rapidly extended to all other provinces of China. ${ }^{6}$ As the number of patients with COVID-19 steadily grew; China began to initiate extraordinary measures. It temporarily closed public transport and locked down entire provinces in China and subsequently, surveillance and emergency preparedness measures were launched.

India issued its first advisory on January 17, 2020. The Emergency Medical Response Unit in the Health Ministry was activated, the National Centre for Disease Control (NCDC) opened a $24 \times 7$ helpline, and the Indian Council of Medical Research (ICMR) worked to quickly put in place a testing facility at National Institute of Virology (NIV), Pune. The Joint Monitoring Group (JMG) under the chairmanship of the Director General of Health Services (DGHS) was initiated to constantly assess the threat and evaluate the preparedness to handle any case that might get imported to India. ${ }^{7}$

\section{Surveillance Strategy}

As soon as the World Health Organization (WHO) sent out a notification on COVID-19 on January 18, all those who are part of the Integrated Disease Surveillance Program (IDSP) and the district surveillance teams were alerted. The WHO guidelines and clinical protocols were circulated to all the districts. Kerala was especially at risk as hundreds of Kerala students, who were pursuing undergraduate medical courses or nursing courses in China, were on their way home. Seventy-two of them were from Wuhan.

As a laboratory confirmed case of COVID-19 reported in Kerala, the Prime Minister's Office and the Ministry of Health \& Family Welfare (MoH \& FW) are closely monitored COVID-19 situation and intensified preparedness and response efforts. Surveillance is being reinforced and intensified at points of entry, in health facilities and in the community including contact tracing and follow up around the confirmed case.

The airport-based surveillance was launched on January 23, 2020. The State COVID-19 cell attached to Directorate of Health Services (DHS), Kerala State, received daily list of average 100-150 persons with a recent travel history to China. Anyone with mild symptoms of flu was directly sent to the isolation wards of selected hospitals in districts. Asymptomatic cases were advised for strict home quarantine.

\section{Quarantine, an Effective Tool to Check Infection Spread}

In recent times, with more knowledge about microbes and their etiology, quarantine strategy has proved beneficial globally to control new and emerging contagious diseases that spread from human to humans. In Kerala, the strategy had been effective earlier in controlling Nipah outbreaks during 2018 and 2019 and now the COVID-19, both zoonotic diseases, with no known drug, except symptomatic treatment. When public health is endangered, people are to be placed under strict quarantine even though they seem asymptomatic, considering that the disease manifest during the incubation period. Based on the reports from various countries, indicated an average incubation period of 5 to 6 days, however can be up to 14 days for $\mathrm{nCoV}$, which was said to spread through droplet discharge-direct or indirect contact. Methods of keeping the infection under control were to place healthy people with high-risk circumstances under home quarantine and moving people with symptoms to hospital isolation setup.

Due to the unknown nature of the virus, double the incubation period has been decided as quarantine period. Kerala is the only state in India that mandates 28 days of home quarantine for those returning from countries affected by COVID-19, while the national guidelines for India is 14 days. ${ }^{8}$ People who are advised home quarantine are advised to stay at their homes during the 28-day period, and report to health care authorities if they show symptoms of coronavirus infection. ${ }^{9}$ People's compliance with the directive would make the strategy successful. The Health Department worked hard to trace the contacts and take protective measures and this helped in containing the infection. With such a precedent, the health team got into action to face $\mathrm{nCoV}$ with a definite action plan and appealed to people with a travel history to China for voluntary quarantine. The district surveillance authorities telephonically contacted those who are in quarantine twice a day and gave counseling and support for their needs.

\section{Details of Second COVID-1 9 Case in India}

As the surveillance, monitoring and contact- tracing exercises are progressing well in the State, the second sample that tested positive for COVID-19 on $1^{\text {st }}$ February 2020 belonged to a companion of the medical student from Thrissur. A 22-year-old second year Medical student, native of Thamarakkulam of Alappuzha district. The travel history is same with that of the first confirmed COVID-19 case hailing from Thrissur. At the airport, on $24^{\text {th }}$ January 
2020, he was received by his father, grandfather and driver and reached home. Seeing an alert about the virus infection, especially those who are coming from Wuhan, on the next day itself, he had gone to the nearest primary health centre at Thamarakkulam. As he did not have any symptoms then, the doctor advised for home quarantine. As his father is working in Vallikkunnam primary health centre, he along with his father had gone to the $\mathrm{PHC}$ on $26^{\text {th }}$ January. He developed fever and diarrhea on the same day, and admitted in the isolation ward of General Hospital, Alappuzha for observation and follow up. His blood/throat swab samples were collected and sent to NIV, Pune for testing. His samples were found positive on $1^{\text {st }}$ February 2020 and he was shifted to Government Medical College Hospital, Alappuzha on the same day. Fifty-nine contacts were traced. Out of this, 09 people developed symptoms. Their samples were sent to NIV, Pune for testing. All the 09 samples have been tested negative.

The patient was strictly monitored and was on under symptomatic management. He was discharged on $13^{\text {th }}$ February 2020 after the consecutive samples were found negative.

\section{Case History of Third COVID-19 Case in India}

The third positive case was confirmed on February 3, 2020. The 23 yr. old COVID-19 positive case, native of Ajanur Panchayath, Kasaragod district, too was a student from Wuhan. His contact tracing turned out to be an exercise in patience and tenacity. On $25^{\text {th }}$ January, he had gone to Kolkata from Guangzhou by Indigo flight and then taken a flight to Bangalore. He travelled in a taxi and stayed at a hotel. On $26^{\text {th }}$ January 2020, he took another taxi and boarded a flight to Kochi. From the airport he took a taxi to Aluva Railway station. From there he took a train to Angamali, stayed at a hotel. On $27^{\text {th }}$ January, he travelled in a Kerala State Road Transport Corporation (KSRTC) bus to Aluva Railway station, and later caught a train to Kanhangad. His friend and his uncle met him at the Railway Station. On $28^{\text {th }}$ January, he contacted heath officials over phone. As he was having no symptoms, the doctors advised for home quarantine. On $30^{\text {th }}$ January 2020, he developed running nose and reached District Hospital, Kanhangad and admitted in the isolation ward. 156 contacts were traced. Out of this, 09 people developed symptoms. Their samples were sent to NIV, Pune for testing. All the 09 samples have been tested negative.

The patient was strictly monitored and was on symptomatic treatment and discharged on 15 February 2020 after consecutive samples were found negative.

First Phase of COVID-I 9 Outbreak in Kerala: Situation Report

On $3^{\text {rd }}$ February 2020, when the third positive case was flagged, the government declared the virus a 'State specific calamity'. The declaration was suddenly withdrawn four days later when there were no more positive cases. From $30^{\text {th }}$ January 2020 to $3^{\text {rd }}$ February 2020, three confirmed cases of COVID-19 were reported in Kerala. By virtue of this, these reports form the first report in our country. In Kerala, as of $5^{\text {th }}$ February, 2,528 passengers returning from China have been identified, out of which 2,435 have been placed under home quarantine and 93 have been admitted to various health facilities, where they are under medical supervision. Till $5^{\text {th }}$ February, 223 samples of suspected cases have been sent to NIV, Pune, of which 193 samples have been tested negative, 3 as positive and results for 27 were pending then. Later the results showed negative. The health officials have been given training in surveillance and contact tracing. Medical specialists were given orientation to provide treatment and care to the patients as per the treatment protocol. Arrangements have been made to control the spread of the disease in all districts of Kerala.

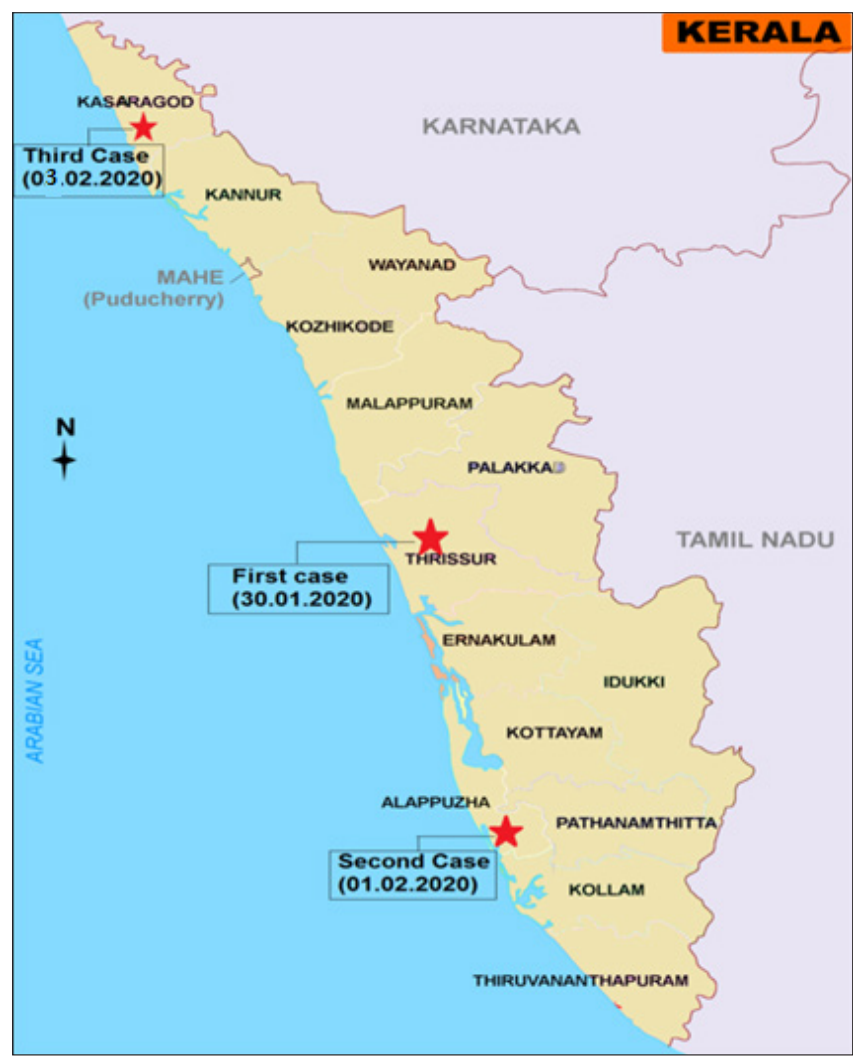

Figure I.COVID- I 9 cases reported in Kerala during the first phase of outbreak

Preparedness for Pandemic Control

The comprehensive lessons and experiences that have resulted from the outbreak of Nipah in 2018 and 2019 provided valuable insight and achievements in how to react to future emerging and re-emerging infectious agents. ${ }^{10}$ Rapid identification of the pathogen via effective diagnostic 
assays is the first step, followed by the implementation of preventive measures, including raising awareness of the new agent, reporting and recording (suspected cases), and infection control management in medical facilities. ${ }^{11}$

For public health awareness program, National Centre for Disease Control (NCDC), Kerala branch, with the consent of Director of Health Services, Kerala State, prepared a leaflet in Malayalam (local language) on $12^{\text {th }}$ February covering all aspects of COVID-19. The leaflet was displayed in all major and minor Railway stations of Southern Zone (Kerala circle) with the whole hearted support and co-operation of Chief Health Inspectors of the Major Railway stations of the state. In additions to this, the leaflets have been provided to District Surveillance Officers (DSOs) of all the 14 districts of Kerala state through the District Education and Media Officers (DEMO). This has been prepared and distributed with an intention to educate the public on the preventive measures to be taken by each individual to contain this infectious disease. More over NCDC, Kerala branch has initiated an awareness campaign in schools with the help of Thaluk HQ Hospital, Cherthala disseminating the importance of Distancing (D), Hand washing $(H)$ and Sanitization practices (S) i.e., DHS. The main function of the Directorate of Health Services (DHS) in a state is the effective utilization and management of resources, logistics, man power, etc. for the betterment of the humanity. Distancing, Hand washing and Sanitization practices (DHS) is also for the betterment of humanity, especially in the era of COVID-19.

The doctors and other health professionals were given proper training regarding the preventive measures and precautions to be taken on the wake of COVID-19 threat in the state. 'Break the Chain' campaign was introduced in the state with an intention to preserve and maintain the cleanliness and hygiene practices among the public. ${ }^{12}$

About 49,702 beds are arranged in Government hospitals for the treatment of COVID-19 patients in the state. Arrangements have been made to treat 1369 patients in Intensive Care Unit (ICU). 800 ventilators are also arranged in Government hospitals. Meanwhile, 81,904 beds are arranged in Private hospitals and also 6059 ICU beds and 1578 ventilators for the treatment of patients. 1205 community kitchens are functioning in Kerala to cater the need of those who are in quarantine/observation and other needy. In addition to this, through 'Kudumbasree Janakeeya hotels', lunch is being given for Rs.20. For guest labors, 19,902 camps have been arranged in various parts of the state for catering the needs of 3, 52,515 labors. Arrangements have been made to feed and provide shelter for the destitute and street wanderers.300 doctors and 400 health inspectors are appointed in the wake of disease outbreak. ${ }^{13}$
In Kerala, where the three people with COVID-19 are quarantined, the health officials have responded very dynamically to curtail further spread of the disease. Kerala has not only traced hundreds of contacts of the confirmed cases and notified them to the Integrated Disease Surveillance Programme (IDSP) for monitoring, but also used unique community-based isolation methods, innovated while dealing with Nipah virus outbreaks.

\section{Challenges Ahead}

Outbreak of Nipah virus occurred for the first time in Kerala in 2018 in Kozhikode district with a death toll of 18. In 2019 the disease again appeared in Ernakulam district, but no deaths were reported. The state has also suffered a lot due to the 2018 and 2019 floods. The ongoing COVID-19 is a much greater concern to the state. The state has won global acclaim in tackling these disasters by closely assessing the situation and utilizing mostly the domestic resources.

During the first phase of disease outbreak, only three cases are reported from the state. As all the 3 cases reported to the nearest Government health care facilities on onset of signs and symptoms, further spread was prevented. The second wave of the infection hit the state when a three-member family returned to Kerala from Italy on $19^{\text {th }}$ February 2020 and tested positive on $8^{\text {th }}$ March. The number of new cases started increased gradually as people who were coming to Kerala from other countries started reporting positive and this peaked on $27^{\text {th }}$ March 2020, when the state had the highest number of 39 new COVID-19 cases being reported on a single day. The state had 1,71,355 persons under surveillance, which was the highest number of people under surveillance so far. However, it has come down to 20,711 on $30^{\text {th }}$ April. Kasaragod, the northernmost district of Kerala reported 178 cases, which is the highest number of COVID-19 cases reported so far in the state.

Globally, as on $30^{\text {th }}$ April, a total of $30,90,445$ confirmed COVID-19 cases and 2, 17,769 deaths were reported, The Case Fatality Rate (CFR) is 7.04\%. In South East Asian Region, 54,021 confirmed cases and 2088 deaths were reported and case fatality rate is $3.86 \% .{ }^{14}$ As the country gears up for a staggered withdrawal of the 40-day lockdown from May, the total number of coronavirus patients in India has gone up to 35,043 while the death toll has reached 1,147 and thus the case fatality rate is $3.27 \% .{ }^{14}$ However, in Kerala, as on $3^{\text {rd }}$ May, a total of $499 \mathrm{nCoV}$ cases were reported with 04 deaths (CFR: $0.80 \%$ ). The number of COVID-19 cases reported in Kerala from 08 ${ }^{\text {th }}$ March to 03rd May 2020 is given in Figure 2. The recovery rate due to $\mathrm{nCoV}$ is highest in Kerala (76.91\%), but in India it is $24.91 \%$. District-wise COVID-19 confirmed cured \& active cases in Kerala as on 30.04.2020 is given in Figure 3 . 


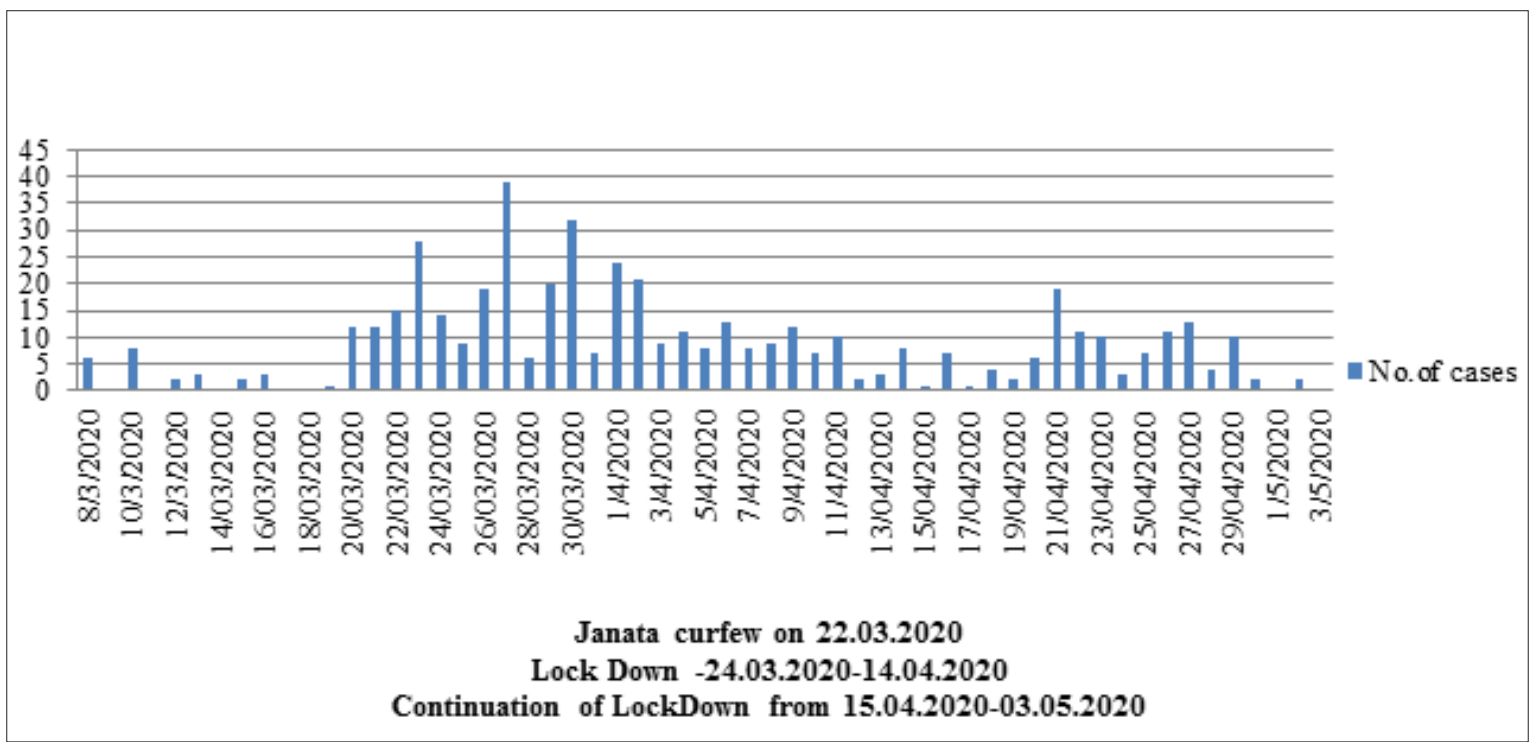

Figure 2.COVID-I 9 cases Reported in Kerala (08 March 2020-04 May 2020)

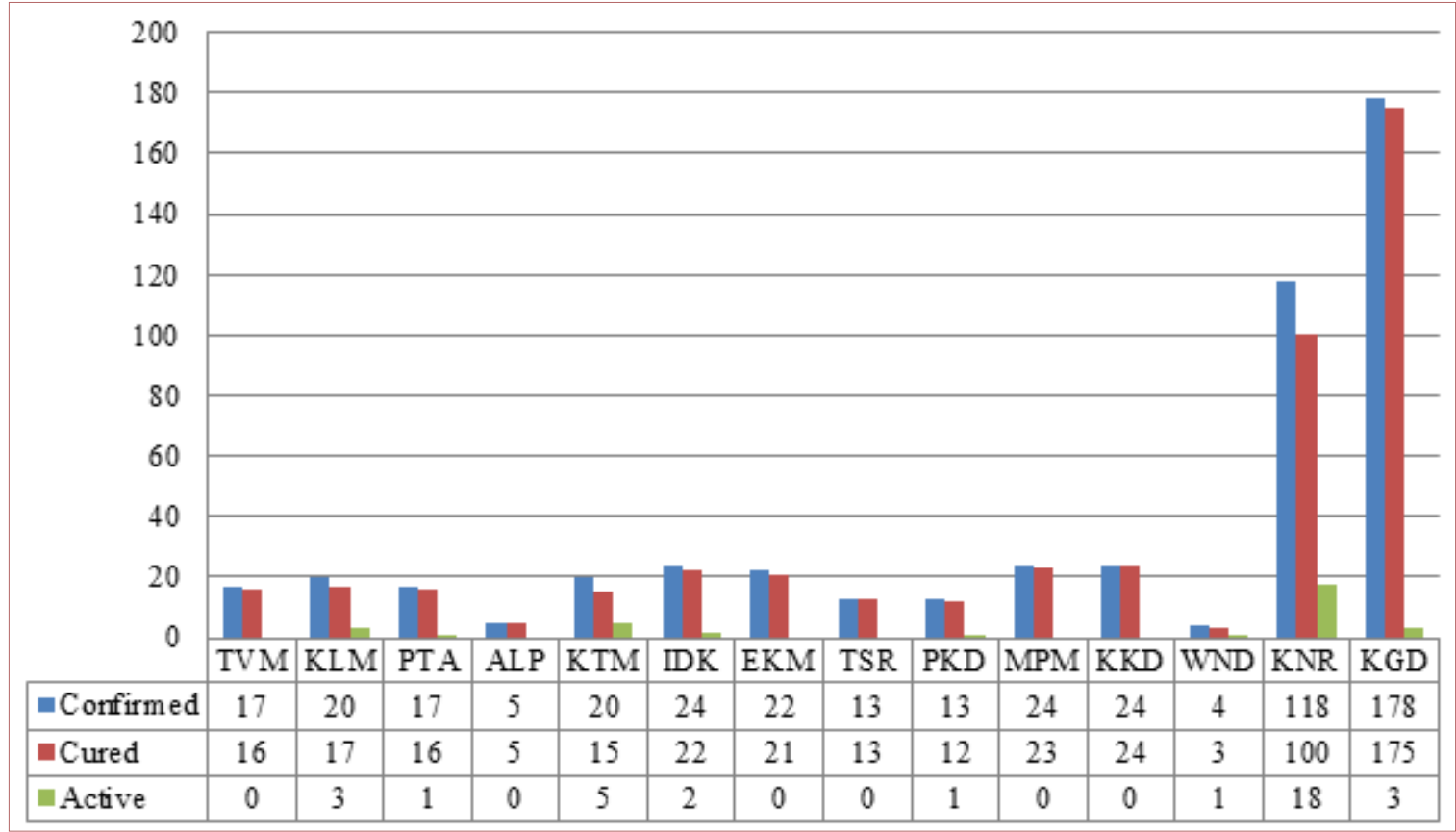

Figure 3.District wise confirmed, cured and active COVID-19 cases (as on 04 May 2020)

In Kerala, always the monsoon is accompanied by vector, water and animal-borne diseases. If there is a relaxation on lockdown after $4^{\text {th }}$ May, the present state of the $\mathrm{nCoV}$ disease situation may change. The forthcoming COVID-19 situation in Kerala may depend on the monsoon, relaxation of lockdown, the entry of Non-Resident Indians (NRIs), the arrival of Keralites from other states, frequent movement of people through the border areas, etc. However, in order to reduce the morbidity due to $\mathrm{nCoV}$, the individuals have to practice good hygiene to prevent further transmission of the virus, such as by washing hands when appropriate (and avoid touching the eyes, nose or mouth with unwashed hands), coughing/ sneezing into a tissue and putting the tissue directly into dust bin and wearing surgical mask. Distancing, Hand washing, Sanitization practices (DHS) are the best measures to prevent COVID-19 infection.

\section{Conclusion}

The lessons and experiences that have resulted from the outbreaks of Nipah, West Nile fever, etc. provide valuable insight and advancements to tackle COVID-19 outbreak in Kerala. The health department has launched a campaign among the public and health workers. Infection control practices have been strengthened in all PHCs, CHCs and Taluk hospitals in the state. Cough corners and airborne infection control corners have been set up in all hospitals as a precautionary measure. 


\section{Acknowledgement}

We thank the District Surveillance Officers of Alappuzha, Thrissur and Kasaragod districts for their help in COVID-19 outbreak investigation. We also thank the Chief Health Inspectors of Southern Railway Zone (Kerala circle) for their relentless service in COVID-19 prevention activities all over the state in association with NCDC, Kerala branch.

\section{Conflicts of Interest: None}

\section{References}

1. Lu R, Zhao X, Li J et al. Genomic characterization and epidemiology of 2019 novel coronavirus; implications for virus origins and receptor binding. Lancet 2020; 395(102240): 565-574.

2. World Health Organization. 2019-nCoV Situation report-22 on 12 February 2020. Available from: https:// www.who.int/docs/default-source/coronavirus/ situation-reports.

3. Galinsky L, Menachery V. Return of the coronavirus: 2019-nCoV. Viruses 2020; 12(12): 135.

4. Chen Z, Zhang W, Lu Y et al. From SARS - CoV to Wuhan 2019-nCoV outbreak: similarity of early epidemic and prediction of future trends. Cell Press, 2020.

5. Maya C. Fighting a virus, yet again. The Hindu, 2020. p.9.

6. WHO. Novel Coronavirus (2019-nCoV). Situation Report-1, 2020.

7. Sudan P, Bhargava L. Prepared for coronavirus. The Hindu, 2020.

8. How Travelers Around the World Are Dealing With 'Voluntary' Home Quarantines Over Coronavirus Fears. Time. Archived on 24 February 2020. Retrieved 9 March 2020.

9. Another Wuhan University Student from Kerala Tested Positive with Novel Coronavirus. Archived on 11 March 2020. Retrieved 9 March 2020.

10. Thomas B, Chandran P, Lilabi MP et al. Nipah virus infection in Kozhikode, Kerala, South India, in 2018: Epidemiology of an Outbreak of an Emerging Disease. Indian J Community Med 2019; 44(4): 383-387.

11. Song $Z, X u Y, B a o L$ et al. From SARS to MERS, thrusting coronaviruses into the Spotlight. Viruses 2019; 11(1): 59.

12. Shailaja KK. How to handle a pandemic. The Hindu, 2020.

13. I \& PRD, Kerala State. Daily Bulletin, 2020.

14. WHO. Coronavirus disease 2019 (COVID-19). Situation Report-100, 2020. 